\title{
Towards Effective Planning and Implementation of the Local Development Initiatives in Limpopo Province, South Africa
}

\author{
Aklilu A. Asha \\ Lecturer, Department of Development Planning and Management, University of Limpopo, \\ aklilu.asha@ul.ac.za
}

\section{Doi:10.5901/mjss.2014.v5n20p398}

Abstract

The post-apartheid South African government has been promoting participatory planning and implementation of local development initiatives through the new system of developmental local governments and integrated development planning approach. The South African local authorities have been producing their Integrated Development Plans (IDPs) since the 2000 local elections. However, the inadequacy in planning and implementation of IDPs hinders the efforts to achieve developmental mandates by local government. This study aims at investigating how to enhance the effectiveness in planning and implementation of IDPs in the local municipalities. The study employed both quantitative and qualitative approaches to collect data from Polokwane, Lepelle-Nkumpi and Aganang local municipalities in Limpopo Province. The finding indicated that the planning and implementation of IDPs has not been effectively addressed by the local municipalities. It was further discovered that the tendency of technocratic top-down approach, failure to fully address the real needs and priorities of the people, lack of mobilistion of locally available resources, difficulty in integration and coordination, poor implementation of projects, and deficiencies in the monitoring and evaluation affects the planning and implementation process of IDPs. Therefore, this study provides the strategic interventions to improve planning and implementation of IDPs. Furthermore, it proposes a framework for strengthening the existing approach to planning and implementation of IDPs. The study is of critical importance in creating a better understanding on enhancing the effectiveness in planning and implementation of IDPs as a tool for developmental local governments in South Africa.

Keywords: Local government, development planning, development implementation, integrated development planning, South Africa, developmental local government.

\section{Introduction}

Participatory local planning and implementation of development initiatives is crucial for improving quality of life at grass root level. It has been noted that many South African local authorities have been producing IDPs, in order to comply with the policy and legal requirements. However, the poor planning and implementation of development initiatives is the biggest challenge in South Africa (Cash \& Swatuk, 2011; Komma, 2012).

This study, therefore, aims at investigating how to further enhance the effectiveness in planning and implementation of IDPs in the local municipalities. The paper is organized as follow: first, it provides the objectives and discussion on literature; secondly, methodology of the study is described; thirdly, it presents the findings as well as a proposed framework; and finally, the paper provides conclusive remarks.

\section{Objectives}

The objective of this study is to investigate how local municipalities can further enhance their effectiveness in planning and implementation of their IDPs in Limpopo Province, South Africa. More specifically:

a) To assess the attitude and perceptions of respondents about the challenges in planning and implementation of municipal IDPs and

b) To propose strategic interventions and a framework for strengthening the existing planning and implementation of municipal IDPs.

\section{Literature Review}

It can be argued that planning and implementation could be considered as major determining factors in relation to the 
outcomes of development process. Therefore, development organizations should critically assess their process of formulating and implementing programmes and policies towards improving people's quality of life. If the goal of development is to reduce poverty and deprivation, then development planning and implementation should be processoriented, people-focused, institution-centred, and based on strategic decisions (Dale, 2004). But what is development planning and implementation?

The term development planning is a concept which is very broad and complex a concept as well as not easy to define because there are no widely accepted definitions and meanings of development planning. Development planning should be understood as a process of formulating and implementing programmes and policies to improve people's quality of life in terms of social, economic, cultural, political and environmental aspects (Dale, 2003; Theron, 2008). To put it differently, development programmes and projects should be focused at grass root level, formulated and implemented by the people and for the purpose of meeting the needs and priorities of the people. This can be best achieved through adoption and implementation of participatory, empowerment, integrated and sustainable approaches in development planning. On the other hand, development implementation involves organisational arrangements, administration and management, execution of project activities, project monitoring and feedback as well as record-keeping (Swanepoel and De Beer, 2011). Hence development implementation refers to the process that involves actual execution of planned activities of a specific development project and programmes.

Hadingham (2003) argues that the South African government has been driving development planning as an integral part of its decentralisation process. Integrated development planning is an important strategic tool for the realisation of development oriented decentralisation as it helps local government to transform its approach of planning and implementation of development initiatives at the local level. Evidences shows that many local authorities have been producing their IDPs, however, there are different problems in terms of institutional capacity for planning and the formulation and implementation of the plan itself (Asha et al, 2013; Reddy, 2010).

According to Harrison (2008), in South Africa, the idea of IDP was first introduced in 1996 when the national government shifted its focus from national and provincial reconstruction to the establishment of a new system of local government throughout the country. The purpose of introducing IDP was to equip the newly established local authorities with a planning tool to improve their performance in coordinated, strategic, developmentally and fiscally responsible manner. Government also put in place support measures such as training for officials and councillors, guide packs and management support to address the initial capacity challenges (Ibid). Integrated development planning can broadly be defined as:

"participatory approach to integrated economic, sectorial, spatial, social, institutional, environmental and the fiscal strategies in order to support the optimal allocation of scarce resources between sectors and geographical areas and across the population in a manner that provides sustainable growth, equity and the empowerment of the poor and the marginalised" (DPLG, 2000:15).

This explanation shows that participation and integration are crucial elements of integrated development planning. Hence, meaningful participation of communities is required in all processes of integrated development planning, mainly in identification of needs and priorities, strategy formulation, project implementation and monitoring and evaluation of achievements (Madzivhandila and Asha, 2012). In addition, improved coordination and the avoidance of fragmented approach to integrated development planning not only promote transparency and accountability but also improve the sharing of ideas and experiences.

According to Venter (2007), integrated development planning should demonstrate the following qualities. It should be integrated; participatory; strategic; and implementation-oriented. First, integration refers to the relationship between municipalities and sector departments as well as the relationship between municipalities and provincial and national government institutions in planning, coordinating and implementation of IDPs. Secondly, participation in IDP involves inclusiveness and representation of all stakeholders in the process of IDP. Thirdly, the strategic nature of IDP refers to the ability of municipalities to choose its priority areas and its ability to successfully and efficiently respond to dynamics in external environments. Finally, implementation-oriented nature refers to the need to successfully execute and avoid delays in implementation of IDP projects (Ibid).

Integrated development planning process involves four interrelated and interdependent stages (DPLG, 2000; Venter, 2007):

- The process begins with the analysis of the existing situation in municipal areas including: compiling existing data; meeting with community and stakeholder representatives; analysing the context of priority issues; and agreeing on priority issues. 
- The second step involves formulation of strategies including agreeing on a vision objectives and making decisions on appropriate strategies taking into consideration application of policy guidelines in the local area.

- The third step focuses on formulation of project proposals.

- The fourth step deals with integration which involves screening adjusting consolidating and agreeing on project proposals followed by compilation of integrated programmes.

- The final step is adoption by councillors through inviting and incorporating comments.

The Municipal Systems Act of 2000 requires all municipalities to adopt a single, inclusive plan for the development of the municipality that links, integrates and co-ordinates plans and takes into account proposals for the development of the municipality and aligns the available resources and capacity with the implementation plan. The inclusive plan also forms the policy frameworks and general foundation on which annual budgets must be based and compatible with national and provincial development plans and planning requirements. The act also provides direction on how to formulate a municipal IDP (South Africa, 2000).

It has been noted that many South African local authorities have been producing IDPs, in order to comply with the policy and legal requirements. Theoretically, IDP helps municipalities to improve service delivery, local democracy and institutional capacity at the local level. Moreover, it facilitates communication, alleviates poverty, facilitates budgeting, ensures local corporate governance and thereby helps to overcome the apartheid legacy in South Africa (Venter, 2007). However, the poor planning and implementation of development initiatives is the biggest challenge in South Africa (Cash \& Swatuk, 2011; Komma, 2012). Davids et al (2009) also identified five pitfalls of IDP, as follows:

- The process is hierarchal, top-down, prescriptive, system-maintaining, blueprint type thinking and planning;

- IDP lacks sense of ownership at community level;

- IDP must be realistic, holistic and suited to the size and capacity of the municipality. It should not raise false expectation;

- IDP must recognize specific conditions and circumstances (question past and existing policies and practices and current reality); and

- Lack of commitment and project management skills.

Studies have also revealed the fact that public participation is limited in Integrated Development Plans (IDPs) (Maphunye and Mafunisa, 2008; Mafunisa and Xaba, 2008). Mafunisa and Xaba indicated that there is inadequate public participation in Limpopo Province due to lack of culture of public participation, lack of information, inadequate skill for public participation, population diversity, and negative attitudes. Another challenge is that lack of alignment in development processes in South Africa (Reddy, 2010). The main challenge lies in poor translation of national development policies and plans into local contexts. It is related to the concern that whether national and provincial priorities are reflected in the municipal IDPs.

Many municipalities are also experiencing shortage of capacity in terms of managing the process of integrated development. Because of this problem, small and rural based municipalities were compelled to outsource planning aspects for external consultants. This had caused chaos in relation to municipal expenses and the actual planning processes because consultants did not have adequate knowledge and understanding about the local situation (Binns and Nel, 2002). Though municipalities significantly reduced dependency on external consultants, integrated development planning processes continue to show inadequate improvement in terms of meaningful participation of public in the decision making process (Tshabalala and Lombard, 2009; Maphunye and Mafunisa, 2008).

The other concern is related to the implementation of IDPs. The violent service delivery protests are an indication of the failure of local governments to achieve their development mandates. Studies have further indicated that the implementation of programmes and projects has been inadequate, slow, had limited impact on lives of beneficiaries, and generally lacks sustainability (Mashamba, 2008; Asmah-Andon, 2009).

The failure of municipal development programmes and projects has contributed to violent service delivery protests across the country from communities angry at the slow pace of service delivery (Malefane, 2009; Nengwekhulu, 2009). The overall situation indicates that local governments, especially in rural areas have been weak in terms of responding to the critical needs of the community at large. It also appears that the support measures taken so far by national and provincial level were inadequate in relation to the magnitude of challenges that local governments are facing towards achieving their developmental mandates. For instance, in Limpopo Province, most of the local governments are still in vulnerable situations in terms of functionality, socio-economic condition and backlog status (COGTA, 2009). The whole situation implies the need to improve local planning and implementation of development initiatives. 


\section{Methodology}

The study area, Limpopo Province, is one of the nine provinces officially recognised in South Africa. The Province is divided into five municipal districts and sub-divided into twenty five rural and urban local municipalities. Geographically, this Province is situated at the north eastern corner of the country. It shares the border with three countries such as Botswana, Zimbabwe and Mozambique. It is also the main gateway to other countries in further field in Sub-Sahara. According to Statistics South Africa (SSA, 2012), the Limpopo Province has a total land area of 125, 754 square kilometres which forms 10.3 percent of the total land area in South Africa. The population of the Province was estimated at 5404868 people which accounts for 10.4 percent of the total population of the country. Regarding the socio-economic situation, the percentage of population and of the total number of households in the Province is steadily growing and this poses additional challenges in planning and implementation of local service and development.

The study employed both quantitative and qualitative approaches. The sampling techniques involved stratified and purposive methods to identify the local municipalities as well as participants of the study for gathering field data. The data was collected by employing a variety of methods including questionnaire, individual interview, group discussion and analysis of available documents.

The quantitative analysis was carried out using descriptive statistics (frequencies, percentages, mean and standard deviation) whereas the qualitative analysis involved field notes, transcription of field notes, categorising the data and interpretation processes.

\section{Key Findings}

\subsection{Biographical Details of Respondents}

The study was undertaken by engaging 83 officers and community representatives from the three local municipalities such as Polokwane, Lepelle-Nkumpi and Aganang. A total of 30 participants participated during the field interview and discussions. Out of the total 30 participants, about $24(80 \%)$ of the respondents were male and $6(20 \%)$ female. Regarding the level of education of participants, $12(40.0 \%)$ hold diplomas and above, $13(43.3 \%)$ completed only grade 12 and the rest, $5(16.7 \%)$ had grade 11 or less. Regarding the positions of participants, about 17 (56.7\%) were community representatives such as ward committee members, traditional leaders, Community Based Organisations (CBOs) and private sectors while 13 (43.3\%) were municipal officers and workers including IDP officers, Local Economic Development (LED) officers, Performance Management System (PMS) Officers and Community Development Workers (CDWs).

On the other hand, a total of 53 respondents were involved in filling the questionnaire for this study. Out of the total 53 respondents, 34 (64.2\%) were male and $19(35.8 \%)$ were female. Regarding age, the mean age of the respondents was 38 years with a standard deviation of 8.8 and it ranges from 19 up to 60 years. Out of 53 respondents, $10(18.9 \%)$, $15(28.3 \%)$ and $28(52.8 \%)$ had grade 11 or less, grade 12, diploma and above, respectively. Out of 53 respondents, 44 (83.0\%) and 9 (17.0\%) were municipal officers/ workers and community representatives, respectively. The mean year of experience of the respondents was 5 years with a standard deviation of 12.3 and it ranges from 1 up to 9 years.

\subsection{Perceptions of Respondents about the Planning and Implementation of IDPs}

It is evident that the planning approach for local development should adopt community based and bottom up system. Respondents from Polokwane indicated that their municipality has adopted the ward level planning approach to identify the needs and priorities of 38 wards. The ward level plan was developed in 2011, 2012 and reviewed in 2013. However, participants indicated that the municipality should move towards budgeting per ward and further decentralize the planning process to village level as a village has its own needs and priorities. Other respondents from Lepelle-Nkumpi revealed that their municipality does not have ward level planning currently.

"Let the IDP be formulated from the grass root, not from the municipality..." said a respondent.

Therefore, this municipality should give attention to start ward level planning in order to create a flat form for communities to share their needs and priorities.

As the local government legislation stipulates, municipal IDPs must reflect the real needs and priorities of the people and bring transformation in local development to empower beneficiary communities. Respondents from 
Polokwane indicated that the IDP contains concerns of the people, for example employing disabled people, braille IDP documents for disabled, access to land for agricultural activities and lack of funding for CBOs. However, the implementation of the concerns is still a challenge because some projects are not in line with the needs and priority of the people. Respondents from Polokwane also indicated the following dissatisfactions with community empowerment: shortage of skills transfer and low level of participation in projects; shortage of skills at community level such as financial management, projects management farming skills, business skills; people must be empowered; and lack of ownership of infrastructures by community. Other respondents from Lepelle-Nkumpi revealed that they have doubts about IDP on reflecting the views and needs and aspirations of people as the majority are not involved in preparation and planning stage. They also indicated their views that the local municipality identify priorities but not in line with people's concerns and fail to properly address such concerns. A respondent commented that:

"The community gives the inputs but they never help us they fail to address the concerns, even if the community give ideas, this document (IDP) never works according to the priority".

The respondents also highlighted that the local people should be empowered by projects (skills, monitoring and tendering processes).

The implementation of municipal IDPs was described in terms of mobilisation of local resources, integration and coordination, project implementation, monitoring and evaluation. It has been argued that the mobilisation of locally available resources may enhance the effectiveness in implementation of municipal IDP projects (Madzivhandila and Asha, 2012). Respondents from Polokwane indicated that there is a need to mobilize locally available resources including project labour and involve private sectors for resource mobilization. First, the municipality has limited resources and it gives priority to areas such as water, electricity and roads. Secondly, engagement of the community is inadequate for implementation of the project. Thirdly, there is limited access to funds and land for developing initiatives. Other respondents from Lepelle-Nkumpi revealed that there are two major challenges with regard to locally available resource mobilization. First, the municipality did not give attention to utilize the resources in the community. Secondly, there is dependency mentality or 'mentality of entitlement' within community.

Venter (2007) pointed out that one of the key characteristics of integrated development planning process is its integrated nature. This includes integration in terms of sectorial departments as well as integration with provincial and national policies and programmes and various stakeholders in planning implementation to achieve stated objectives. Respondents from Polokwane revealed that the relationship between local municipalities, sector departments and community needs to be strengthened based on the principle of cooperation. The municipality is facing lack of integration due to the following challenges: departments are doing for compliance and fail to implement the projects they submitted; the alignment of projects in the IDP is a challenge due to difficulties to get support from all sectors and stakeholders; the municipalities and departments are not fully working in close collaboration; the relationship between departments and community needs to be strengthen; traditional leaders need to plan together with municipality in terms of efficient utilization and management of land; and the role of IDP offices not fully understood by other departments.

Other respondents from Lepelle-Nkumpi indicated that there is lack of integration due to inadequate relationships between the municipality and sector departments. The following are issues of concern: alignment of resources is poor; duplication of events and activities; weak interaction between departments (LED) and town planning; all departments should be actively involved in the process; there are instances where departments did not consult IDP; not yet integrated in terms of providing services; and the municipalities and departments are not adequately cooperating with regard to assisting private sectors.

The nature of South African IDPs is that they are implementation-oriented. Put differently, the most important thing is translating the IDP documents into a reality to improve services and development at the local level (Venter, 2007). Hence, projects contained in the municipal IDPs need to be implemented properly to achieve the development policy mandates of local authorities. Respondents from Polokwane revealed that the municipality is using Service Delivery Implementation Plan (SDIP) which shows project quarterly milestone. Regarding project implementation, there are successful and failed projects. A participant highlighted that:

"Community members complain to the IDP office about non implemented projects, about the projects cancelled by departments."

A number of challenges have contributed to poor implementation of IDP projects. These include: delays in implementation of IDP projects; backlog (e.g. water projects, RDP houses); limited benefits from projects (e.g. taps are there but no water, hire few people); failure to involve the community in project implementation; and lack of capacity of 
project steering committee. Other respondents from Lepelle-Nkumpi indicated the problem of inadequate implementation of projects and lack of sustainability in terms of continuation. In this regard, participants have indicated their observations as follows: the project steering committee not performing well; poor oversight of the project; projects rollovers; departments implement projects which are not part of IDPs; slow implementation of projects; and lack of regular consultation with ward committee.

Monitoring and evaluation are important tools to ensure the effectiveness of development plans at the local level. Respondents from Polokwane revealed that the current practice of IDP monitoring and evaluation at the local level involves the following procedures. First, COGTA evaluate the credibility of the municipal IDP, whether it complies with the requirements, advert of invitations, strategic planning workshops. Secondly, the municipality transfers all the projects in the IDP into SDIP, then the directors sign performance agreement. Thirdly, performance management office quarterly evaluates the performance of directorates in a formal meeting with members of the mayoral committee. Fourthly, the municipal public account committee goes out randomly to check on projects in the field.

However, there are deficiencies in the current system of monitoring and evaluation of IDPs listed as follows: the IDP office is not allowed to visit or supervise the actual implementation of the project; no proper documentation; performance management office lacks capacity; lack proper handover of the project together with all stakeholders; the ward committee should become part of monitoring committee; IDP is reviewed annually by internal stakeholders outsiders view must be considered; the IDP office should be responsible for driving the monitoring and evaluation process for IDP; and the ward committee meeting is on monthly basis. The ward committee submits a number of issues to the speaker's office, but the right office would be the IDP office.

Likewise, other respondents from Lepelle-Nkumpi added several challenges in relation to the current procedures of monitoring and evaluation of IDPs such as: lack of capacity (technical staff and resources) to follow-up projects; doing review for the sake of compliance; low level of attendance by the community in annual IDP review; inadequate involvement of CDWs and ward committees in monitoring; project steering committee are trained but they lack capacity to supervise technical aspects of projects; IDP office is not involved in monitoring; the business sector should participate in monitoring and evaluation; the municipality doesn't participate in CBOs in monitoring and evaluation; and every month ward committee submit reports but we (IDP office) don't get feedback and this creates information gap.

\subsection{Analysis of Degree of Response in relation to the Planning and Implementation of IDPS}

Local municipalities are obliged to prepare a comprehensive plan of their development agenda using integrated development planning approach. The following analysis provides the degree of responses, mean and standard deviation in relation to the effectiveness in planning IDPs at local level (Table 1). The construct the effectiveness in preparation and planning of IDPs' consisted of seven statements listed as follow:

- Statement C1- The IDP process is very complex to the level that local municipalities can hardly understand and implement.

- Statement C2- There is difficulty in identification of intended beneficiaries for programmes and projects within the municipality.

- Statement C3- There is inadequate baseline data for planning services and infrastructural provisions.

- Statement C4- Lack of meaningful participation of the public in decision making process is affecting the implementation of IDP.

- Statement C5- There is a concern regarding whether the IDP reflects the true needs and priorities of the most vulnerable groups in communities.

- Statement C6- The municipality's IDP preparation process needs further strengthening.

- Statement C7- Inadequate targeting of disadvantaged groups in communities is affecting the implementation of IDP. 
Table 1. Degree of response related to the effectiveness in planning of IDPs $(n=53)$

\begin{tabular}{|c|ccccccc|}
\multicolumn{1}{c|}{ Item } & Percentage \% & & & \\
& Strongly disagree & Disagree & Undecided & Agree & Strongly Agree & Mean & SD \\
Statement C1 & 25.0 & 20.0 & 7.5 & 27.5 & 20.0 & 2.98 & 1.527 \\
Statement C2 & 2.5 & 42.5 & 10.0 & 32.5 & 12.5 & 3.10 & 1.172 \\
Statement C3 & 5.0 & 17.5 & 20.0 & 45.0 & 12.5 & 3.43 & 1.083 \\
Statement C4 & 7.5 & 17.5 & 2.5 & 50.0 & 22.5 & 3.63 & 1.234 \\
Statement C5 & 10.0 & 30.0 & 10.0 & 22.5 & 27.5 & 3.28 & 1.414 \\
Statement C6 & 0.00 & 22.5 & 2.5 & 42.5 & 32.5 & 3.85 & 1.122 \\
Statement C7 & 10.0 & 22.5 & 7.5 & 40.0 & 20.0 & 3.38 & 1.314 \\
\hline
\end{tabular}

Source: own survey data, 2014

According to Table 1, the highest (mean=3.85) of statement C6 which states 'the municipalities IDP preparation needs further strengthening', implies the need to improve planning of IDPs at the local municipalities level, when compared to the other items. The second item with high mean is the statement $\mathrm{C} 4$ (mean=3.63) 'lack of meaningful participation of the public in decision making processes is affecting the implementation of IDP'. This statement also suggests improving the quality of participation in IDPs. The third highest mean (3.43), i.e. statement C3 states 'there is inadequate baseline data for planning services and infrastructure provisions' also reveals the need to improve the planning process. On the other hand, the mean score of $\mathrm{C} 1$ and $\mathrm{C} 2$ were the lowest among seven statements and all were negative. The low mean score and the negative sign of these indicators suggest that respondents tend to disagree with the view that the planning process of IDP is inadequate in the local municipalities. The aforementioned analysis on the degree of responses with regard to the preparation and planning of IDP reveals mixed response i.e. some agree and some disagree. However, most of the respondents indicated that the planning process of IDP is inadequate in the local municipalities due to key factors such as lack of quality participation and lack of baseline data.

The following Table 2 shows the degree of response, mean and standard deviation in relation to the implementation of IDP at the local level. The construct 'the effectiveness in the implementation of IDPs' consisted of 12 statements listed as follow:

- Statement C8- Weak cooperation among departments and the municipal office is affecting the implementation of IDP.

- Statement C9- Programmes and projects has been inadequate, slow, had limited impact on lives of beneficiaries.

- Statement C10- Lack of alignment is affecting the implementation of IDP.

- Statement C11- The municipality has done inadequately in providing clean water to its residents.

- Statement C12- The municipality has done inadequately in providing formal houses to its residents.

- Statement C13- The municipality has done inadequately in providing electricity to its residents.

- Statement C14- The municipality has done inadequately in providing toilet facilities to its residents.

- Statement C15- The municipality has done inadequately in providing refuse removal to its residents.

- Statement C16- The municipality has done inadequately in developing entrepreneurship.

- Statement C17- The municipality has done inadequately in creating job opportunities to its residents.

- Statement C18- The municipality has done inadequately in training and building the skills of its residents.

- Statement C19- The municipality's monitoring and evaluation process of IDP needs further strengthening. 
Table 2. Degree of response related to the implementation of IDPs $(n=53)$

\begin{tabular}{|c|c|c|c|c|c|c|c|}
\hline \multirow[t]{2}{*}{ Item } & \multicolumn{7}{|c|}{ Percentage \% } \\
\hline & Strongly disagree & Disagree & Undecided & Agree & Strongly Agree & Mean & SD \\
\hline Statement C8 & 10.0 & 10.0 & 10.0 & 42.5 & 27.5 & 3.68 & 1.269 \\
\hline Statement C9 & 2.5 & 22.5 & 17.5 & 27.5 & 30.0 & 3.60 & 1.215 \\
\hline Statement C10 & 0.00 & 15.0 & 10.0 & 47.5 & 27.5 & 3.88 & 0.992 \\
\hline Statement C11 & 12.5 & 27.5 & 15.0 & 17.5 & 27.5 & 3.20 & 1.436 \\
\hline Statement C12 & 10.0 & 27.5 & 12.5 & 27.5 & 22.5 & 3.25 & 1.354 \\
\hline Statement C13 & 22.5 & 32.5 & 7.5 & 22.5 & 15.0 & 2.75 & 1.428 \\
\hline Statement C14 & 12.5 & 22.5 & 15.0 & 30.0 & 20.0 & 3.23 & 1.349 \\
\hline Statement C15 & 25.0 & 25.0 & 10.0 & 17.5 & 22.5 & 2.88 & 1.539 \\
\hline Statement C16 & 22.5 & 35.0 & 10.0 & 15.0 & 17.5 & 2.70 & 1.436 \\
\hline Statement C17 & 22.5 & 30.0 & 10.0 & 17.5 & 20.0 & 2.83 & 1.483 \\
\hline Statement C18 & 25.0 & 12.5 & 17.5 & 22.5 & 22.5 & 3.05 & 1.518 \\
\hline Statement C19 & 12.5 & 7.5 & 15.0 & 30.0 & 35.0 & 3.68 & 1.366 \\
\hline
\end{tabular}

Source: own survey data, 2014

As indicated in Table 2, the highest (mean=3.88) of statement $\mathrm{C} 10$ which states 'lack of alignment is affecting the implementation of IDP', implies that alignment is poor in the implementation of IDP, when compared to the other items. The second item with high mean is the statements $\mathrm{C} 8$ and $\mathrm{C} 19$ (mean=3.68). The former statement (C8) suggests that weak cooperation among departments and municipal officials is affecting the implementation of IDP whereas the later statement (C19) entails that the municipalities' monitoring and evaluation process of IDP needs further strengthening. The third highest mean (3.60), i.e. statement C9 'programmes and projects has been inadequate, slow had limited impact on the lives of beneficiaries also reveals the need to improve the implementation process. On the other hand, the mean score of $\mathrm{C} 13, \mathrm{C} 15, \mathrm{C} 16, \mathrm{C} 17$ and $\mathrm{C} 18$ were the lowest among 12 statements and all were negative. The low mean score and the negative sign of these indicators suggest that respondents tend to disagree with the view that the implementation of IDP is insufficient in the local municipalities. The aforementioned analysis reveals that the degree of response with regard to the implementation of IDP is 'mixed' meaning that some agree and others disagree. However, most of the respondents indicated that the implementation of IDP is inadequate in the local municipalities due to key challenges including poor alignment, the inadequate and slow implementation of projects.

\subsection{Analysis of the Overall Attitude of Respondents on the Planning and Implementation of IDPs}

The following results of quantitative analysis indicate the attitude of participants on the preparation and planning of IDPS in the local municipalities.

Table 3. The overall attitude of respondents towards effectiveness in planning of IDPs by categories of local municipalities $(n=53)$

\begin{tabular}{|l|c|c|c|c|c|c|c|c|}
\hline \multirow{2}{*}{ Category of local municipality } & \multicolumn{2}{|c|}{ SD \& DA } & \multicolumn{2}{c|}{ Undecided } & \multicolumn{2}{c|}{ SA \& AG } & \multicolumn{2}{c|}{ Total } \\
\cline { 2 - 9 } & Freq. & $\%$ & Freq. & $\%$ & Freq. & $\%$ & Freq. & $\%$ \\
\hline Urban (Polokwane) & 5 & 9.42 & 1 & 1.89 & 9 & 16.99 & 15 & 28.30 \\
\hline Rural (Lepelle-Nkhumpi and Aganang) & 10 & 18.87 & 4 & 7.55 & 24 & 45.28 & 38 & $\mathbf{7 1 . 7 0}$ \\
\hline \multicolumn{1}{|c|}{ Total } & $\mathbf{1 5}$ & $\mathbf{2 8 . 3 0}$ & $\mathbf{5}$ & $\mathbf{9 . 4 4}$ & 33 & $\mathbf{6 2 . 2 7}$ & $\mathbf{5 3}$ & 100.00 \\
\hline
\end{tabular}

Source, own survey, 2014; SD= Strongly Disagree; DA=Disagree; SA= Strongly

Agree; AG= Agree.

The comparative analysis on overall attitude of respondent's in relation to the preparation and planning of IDPs in the local municipalities reveals that the significant proportion $33(62 \%)$ of the respondents tend to support the view that the planning process of IDP needs further improvement in the local municipalities; while $5(9 \%)$ of them remained undecided. The rest $15(28 \%)$ of them tend to disagree with the view (Table 3 ).

The following results of quantitative analysis indicate the attitude of participants on the implementation of IDPs in the local municipalities. 
Table 4. The overall attitude of respondents towards effectiveness in implementation of IDPs by categories of local municipalities $(n=53)$

\begin{tabular}{|c|c|c|c|c|c|c|c|c|}
\hline \multirow{2}{*}{ Category of municipality } & \multicolumn{2}{|c|}{ SD \& DA } & \multicolumn{2}{c|}{ Undecided } & \multicolumn{2}{c|}{ SA \& AG } & \multicolumn{2}{c|}{ Total } \\
\cline { 2 - 10 } & Freq. & $\%$ & Freq. & $\%$ & Freq. & $\%$ & Freq. & $\%$ \\
\hline Urban (Polokwane) & 6 & 11.32 & 2 & 3.77 & 7 & 13.21 & 15 & 28.30 \\
\hline Rural (Lepelle-Nkhumpi and Aganang) & 12 & 22.64 & 6 & 11.32 & 20 & 37.74 & 38 & 71.70 \\
\hline Total & 18 & 33.96 & 8 & 15.09 & 27 & 50.95 & 53 & 100.00 \\
\hline
\end{tabular}

Source, own survey, 2014; SD= Strongly Disagree, DA=Disagree, SA= Strongly Agree, AG= Agree.

The comparative analysis on overall attitude of respondent's in relation to the implementation of IDPs in the local municipalities reveals that almost 27 (51\%) of the respondents tend to support the view that the implementation of IDP is problematic due to various factors that affect the local municipalities; while $8(15 \%)$ of them remained undecided. The rest $18(34 \%)$ of them tend to disagree with the view.

\section{Proposed Framework for Strengthening the Planning and Implementation of IDPs}

The following framework shows strengthening or improving the effectiveness in planning and implementation of IDPs in the local municipalities understudy in Limpopo.

\subsection{Analysis Stage}

There is a need for grassroots bottom-up participation as "IDPs are often-control oriented and follow rigid guidelines" (Theron and Ceasar, 2008: 117). According to the proposed framework (Figure 1), the local municipalities planning processes of IDPs should further encourage the ward-level planning and budgeting in order to promote bottom-up participation. There are two important things in the ward-level planning. The ward-level planning should not only focus on the needs and priorities of people but it should also emphasize on the available potentials and capabilities within each ward so as to mobilize locally available resources. Korten (1990) pointed out that mobilization of local resources creates sustainable and equitable improvements in people's quality of life. Additionally, the planning process of IDPs should emphasize on identification of the existing institutional capacity (human, financial and material resources) at the local municipality level. In other words, it must be institutional-sensitive so as to match the municipal capabilities with developmental objectives and the context.

Figure 1. Framework for strengthening the planning and implementation of IDPS

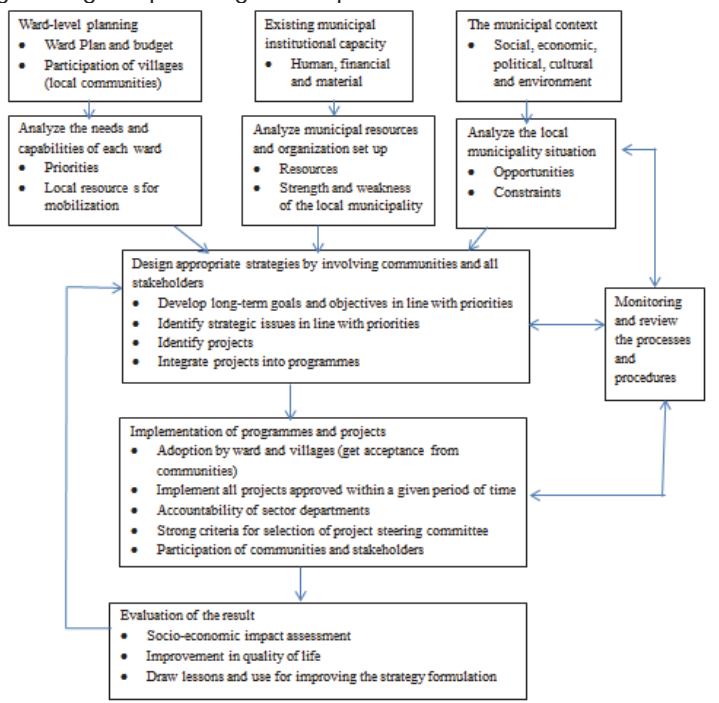




\subsection{Strategy Design}

It is important that communities and all stakeholders should take part in designing the strategy for IDPs (Figure 1). Furthermore, the local municipalities should be capable of carrying out their strategic planning processes of IDPs. As Theron and Ceasar (2008: 116) comment, "inefficient capacity among local government to manage IDPs has turned out local governments into proverbial "cash cows" for development consultants".

There is a need to properly align projects with the strategic objectives of municipal IDPs and required budgets or resources. The IDP documents should not contain a wish list of projects. Only relevant projects with the possibility to be implemented should appear in the IDP. Additionally, the local municipalities should engage all stakeholders including traditional leadership and communities in identification of IDP projects because the projects should also be aligned with the needs and priorities of the people. Goldman and Reynolds (2008) noted that rural municipalities face overwhelming challenges in terms of budgeting and human capacity. Therefore, proper integration of sector plans and projects in the IDP reduces duplication of efforts and ultimately contributes to efficient alignment and utilisation of scarce resources at the local municipality.

\subsection{Implementation of Programmes and Projects}

The local municipality should also improve the adoption process by taking it further to the ward and village levels because it is important to get acceptance from the community and community representatives (Figure 1). This would help to create better sense of ownership of IDPs by communities. Poor implementation of development plans is a major challenge facing government in developing countries. In this regard, Theron (2008) argues that "a weakness of contemporary planning in developing countries is the absence and failure of the implementation of plans. Usually too much time is spent on planning and too little on implementation". The community complain about incomplete projects by sector departments. Hence, the local municipalities should force all heads of departments to sign before submission of their sector projects so as to make them bind for implementation of IDP projects. Sector departments should also be accountable to the local ward and village in terms of projects. The local municipalities should also re-establish strong criteria for selection of project steering committees.

\subsection{Monitoring, Review and Evaluation}

Generally, IDPs lack of appropriate monitoring and evaluation procedures caused failures and disillusionment (Davids et al, 2009). To improve the effectiveness in planning and implementation of IDPs, local municipalities should ensure that each and every stage in integrated development planning process is monitored regularly. The feedback should be utilised to improve the processes and procedures of IDPs as indicated in figure 1. The monitoring of IDPs should be seen as a continuous process of promoting social learning. In addition to regular monitoring, participation by all stakeholders is crucial for effective monitoring (Burkey, 1993) of IDPs and promote social learning. Local municipalities should therefore involve relevant stakeholders in monitoring and make sure that their monthly, quarterly, bi-annual and annual IDP assessment reports are available to all stakeholders. This requires proper documentation of follow up reports by mayoral committee/ municipal public account committees.

At present all projects in the IDPs are transferred to SDIP and then the responsible directors or managers sign performance agreements. Performance management offices monitor quarterly the performance of responsible directors or managers in a formal meeting with members of mayoral committees. The local municipality should cascade the quarterly performance monitoring to the lower levels such as managers and assistant managers or coordinators because managers and coordinators are more responsible for project specifications and appointment of service providers, so they should be part of the monitoring processes. The local municipalities should consider the need to strengthen monitoring and evaluation of IDPs. The IDP office should be responsible for driving the monitoring and evaluation of IDPs by developing and putting in place an appropriate system (Figure 1).

Review of IDP should not be done for the sake of compliance. Key stakeholders including the community, ward committee, CDWs and project steering committee should be involved in the process of reviews. More attention should be given to the level of empowerment of citizens, especially the poor and on the ability of municipalities to deliver effective and co-ordinated services to citizens as suggested by Cameron (cited in Harrison, 2008). Additionally, there should be an overall terminal evaluation on the effectiveness and impact of the five year IDPs. This type of evaluation should include the view of insiders and outsiders. It is crucial to properly document the evaluation reports with the view to draw a lesson from previous five years and improve the new ones. 


\section{Conclusion}

In conclusion, the proposed frameworks for strengthening the planning and implementation of IDPs be implemented, evaluated and integrated into the current IDP processes of the Polokwane, Lepelle-Nkumpi and Aganang local municipalities in Limpopo. Further research should also be done on the implementation of proposed frameworks to evaluate what effective planning and implementation of IDPs would have on the quality of people's life at grass root level.

\section{References}

Asha A., Belete, A., Moyo, T. (2013). Analyzing decentralization and local government's role in development in South Africa. Journal of African and Asian Local Government Studies, 2 (2): 94-107.

Asmah-Andon, K. (2009). Implementation of Developmental Local Government for Alleviating poverty and Inequality. Journal of Public Administration, 44 (1.1):100-110.

Binns, T. and Nel, E. (2002). Devolving development: Integrated development planning and developmental local government in postapartheid South Africa. Regional studies, 36 (8): 921-945.

Burkey, S. (1993). People First: a guide to self-reliant, participatory rural development. London: Zed books Ltd.

Cooperative Governance and Traditional Affairs (COGTA). (2009). State of local government in South Africa. Pretoria: COGTA.

Cash, C. and Swatuk, L. (2011). Integrated development planning in South Africa: lessons from Dwars River Valley. Urban Forum, 22: 53-73.

Dale, R. (2003). The logical framework: an easy escape, a straitjacket, or a useful planning tool? Development in Practice, 13 (1): 57-91.

Dale, R. (2004). Development Planning: Concepts and Tools for Planners, Managers and Facilitators. London: Zed Books.

Department of Provincial and Local Government (DPLG). (2000). IDP guides pack. Government printer: Pretoria

Department of Provincial and Local Government (DPLG). (2000). A policy paper on integrated development planning. Government printer: Pretoria.

Davids, I., Theron, F. and Maphunye, K. (2009). Participatory development management in South Africa: A development management perspective, $2^{\text {nd }}$ edition. Pretoria: Van Schaik.

Hadingham, T. (2003). Decentralisation and development planning: some practical considerations. Retrieved on 03/05/2014 from www.ilo.org/wcmsp5/groups/public/@ed_emp/@emp_policy/@invest/documents/publications/wcms_asist_8213.pdf

Harrison, P. (2008). South Africa's integrated development plans, in Pieterse, E. Parnell, S. Swilling, M. \& Van Donk, M. (eds.), Consolidating developmental local government. Cape Town: UCT.

Korten, D. (1990). Getting to the 21st Century: Voluntary action and the global agenda. Connecticut: Kumarian Press.

Komma, S. B. (2012). The evolution of developmental local government in South Africa: Issues, trends and options. Journal of US-China Public Administration, 9 (1): 53-67.

Malefane, S. (2009). Structuring South African municipalities for effective Local Economic Development (LED) implementation. Journal of Public Administration, 44 (1.1): 156-168.

Mafunisa, M. \& Xaba, B. (2008). Public Participation and the Integrated Development Planning: The Case of Limpopo province. Journal of Public Administration, 43, 452-460.

Madzivhandila, T. and Asha, A. (2012). Integrated development planning process and service delivery challenges for South Africa's local municipalities. Journal of Public Administration, 47 (1.1): 369-378.

Mashamba, N. (2008). The state of IDP in the Limpopo Province. 2008. Journal of public Administration, 43 (3.2): 421-435.

Maphunye, K. and Mafunisa, M. (2008). Public participation and the Integrated Development planning process in South Africa. Journal of Public Administration, 43(3.2):461-472 .

Mafunisa, M. \& Xaba, B. (2008). Public Participation and the Integrated Development Planning: The Case of Limpopo province. Journal of Public Administration, 43 (3.2): 452-460.

Nengwekhulu, R.H. (2009). Public service delivery challenges facing the South African public service. Journal of public administration, 44(2):341-363.

Reddy, P. \& Sikhakane, B. (2008). Public Participation: a case study of ward committees in Buffalo city municipality. Journal of Public Administration, 43 (4.1): 680-696.

South Africa. (2000). Local Government Municipal Systems Act 32 of 2000. Pretoria: Government Printer.

Statistics South Africa (SSA). (2012). Limpopo provincial profile. Pretoria: SSA. Available: www.statssa.gov.za/publications/ Report00.../Report-00-91- 092004.pdf (21/01/2014)

Swanepoel, H. and De Beer, F. (2011). Community development: breaking the cycle of poverty, $5^{\text {th }}$ edition. Lansdowne, South Africa: Juta.

South Africa. (2000). Local Government Municipal Systems Act 32 of 2000. Pretoria: Government Printer.

Theron, F. (2008). The change agent-project beneficiary partnership - theoretical perspective, in Theron, F. (ed.), the development change agent: a micro-level approach to development. Pretoria; Van Schaik publishers.

Tshabalala, E.L and Lombard, A. (2009). Community participation in the integrated development plan: a case study of Govan Mbeki municipality. Journal of Public Administration, 44 (2):396-409.

Theron, F. and Ceasar, N. (2008). Participation - a grass root strategy for development management, in Theron, F. (ed.), the development change agent: a micro-level approach to development. Pretoria; Van Schaik publishers.

Venter, A. (2007). Integrated development planning as an approach to sustainable development, in Van der waldt (ed.), Municipal management: serving the people. Cape Town: Juta. 